\title{
Autotrophic deodorization of hydrogen sulfide in a biotrickling filter
}

\author{
Yaomin Jin, María C Veiga, Christian Kennes \\ Journal of Chemical Technology \& Biotechnology, Volume 80, Issue 9, September \\ 2005, Pages 998-1004 \\ DOI: $10.1002 /$ jctb.1275
}

\begin{abstract}
The removal of hydrogen sulfide $\left(\mathrm{H}_{2} \mathrm{~S}\right)$ from airstreams was studied in a biotrickling filter (BTF) packed with plastic Pall rings operating with counter-current flows of the air and liquid streams. Experiments were performed at different inlet $\mathrm{H}_{2} \mathrm{~S}$ concentrations, air and/or liquid volumetric flow rates, and sulfate concentrations in the recirculating liquid to check their effect on the performance of the BTF. Conversion of $\mathrm{H}_{2} \mathrm{~S}$ never dropped below $80 \%$ at the highest concentration and reached $100 \%$ at low concentrations. A maximum removal rate of $22.5 \mathrm{~g} \mathrm{H}_{2} \mathrm{~S} \mathrm{~m}^{-3}$ reactor $\mathrm{h}^{-1}$ was observed with $100 \%$ removal efficiency. The shortest empty bed retention time studied at which complete $\mathrm{H}_{2} \mathrm{~S}$ removal was observed was around $11 \mathrm{~s}$. Conversion of $\mathrm{H}_{2} \mathrm{~S}$ was found to slightly increase as the liquid flow rate decreased and as the air flow rate increased.
\end{abstract}

\section{Keywords:}

autotroph; biotrickling filter; hydrogen sulfide; pall rings

\section{INTRODUCTION}

Hydrogen sulfide $\left(\mathrm{H}_{2} \mathrm{~S}\right)$ is released to the atmosphere as a by-product of industrial processes including sour gas flaring, petroleum refining, wastewater treatment, and pulp and paper manufacturing. Besides being toxic, $\mathrm{H}_{2} \mathrm{~S}$ is a nuisance odour and shows negative effects on the environment. Exposure to $\mathrm{H}_{2} \mathrm{~S}$ is harmful to crops and vegetation and is highly corrosive to materials. A maximum safe exposure limit of this compound is $10 \mathrm{ppm}$, but the odour from this gas can be detected to concentrations below 0.47 ppb. Emissions of hydrogen sulfide contribute to nuisance odours smelling like rotten eggs. For these reasons, strict regulations are necessary for controlling the emissions. Only highly efficient odour control systems can remove $\mathrm{H}_{2} \mathrm{~S}$ to very low levels. 1

Biofiltration is a promising technology involving the flow of a polluted air stream through a packed-bed containing microorganisms that are able to degrade pollutants into harmless products. Biofiltration is a viable and potentially cost-effective alternative to conventional technologies for the treatment of low-concentration polluted air streams. It is characterized by low operating/energy costs resulting from the utilization of microbial oxidation processes at ambient conditions instead of oxidation by thermal or chemical means. Under the proper conditions, high removal efficiencies can be achieved and the process is environmentally friendly since the end-products are basically harmless or even reusable.2-4 
While biofiltration has emerged as an attractive technique in the treatment of waste gases, it is not completely free of problems and still needs to be further optimized. One problem is that in gas streams containing $\mathrm{H}_{2} \mathrm{~S}$, the biofilter often gets acidified while partly losing its activity. Although several biofilters have originally been applied to the control of odours and $\mathrm{H}_{2} \mathrm{~S}$ emissions, a number of studies have reported problems associated with the biodegradation of hydrogen sulfide.5-9 The oxidation of $\mathrm{H}_{2} \mathrm{~S}$ in the biofilter bed produces sulfuric acid and sometimes elemental sulfur. The optimal $\mathrm{pH}$ for many aerobic $\mathrm{H}_{2} \mathrm{~S}$-degrading bacteria is slightly acidic, but the presence of sulfuric acid results in $\mathrm{pH}$ drops down to very low values, which in turn reduces the solubility of $\mathrm{H}_{2} \mathrm{~S}$ in the aqueous phase, slows down the mass transfer of $\mathrm{H}_{2} \mathrm{~S}$ in the liquid phase, and inhibits the activity of microorganisms.9 To control the $\mathrm{pH}$ of the medium, buffering agents may be added in the form of calcium carbonate, dolomite or oyster shells. The medium may also be washed to help control the $\mathrm{pH}$. However, when using an organic carrier as compost, the spent minerals and acid-degraded compost often form small particles and contribute to biofilter clogging. In practical applications, it is difficult and expensive to control the $\mathrm{pH}$ and the medium is often replaced when the alkalinity is completely exhausted.10 The accumulation of elemental sulfur may also result in clogging of the biofilter bed.

As mentioned above, compost is still one of the most widely used biofilter media. It is inexpensive, nutrient rich, and has a substantial adsorption capacity. The microorganisms remaining from the composting process constitute an excellent inoculum and the medium rapidly becomes effective at removing air pollutants. Most microorganisms present in such a type of organic carrier are heterotrophs. Although compost has been used in biofilters treating $\mathrm{H}_{2} \mathrm{~S}$ in many studies,9, 11-14 the life span of that packing material is limited to a maximum of about 7 years, and is commonly much shorter.15 Compost decays over time, causing compaction, clogging, short circuiting and increased headloss across the bed. In one example, a compost biofilter treating approximately 30 parts per million of $\mathrm{H}_{2} \mathrm{~S}$ at a flow rate of 2700 cubic feet per minute, the life span of the compost was only four months.9 Besides, compost shrinks and cracks, causing air short circuiting if too much biomass is produced or if the medium dries out. In comparison, inorganic media are not prone to compaction or shrinking and will last almost indefinitely. If they dry out, rewetting is not difficult. However, most of them are more expensive than compost and all require nutrients to be added.10 In the case of inert and inorganic carriers, an additional carbon source needs to be added if one wants to promote the growth of heterotrophic organisms. However, this is not necessary in the case of autotrophic $\mathrm{H}_{2} \mathrm{~S}$-removal.

In the present study a biotrickling filter was packed with Pall rings as support for autotrophic microorganisms used to treat $\mathrm{H}_{2} \mathrm{~S}$-polluted air, and to determine the operating parameters that optimize the performance of such a system.

\section{MATERIAL AND METHODS}

\section{Microorganisms and cultivation}

An autotrophic $\mathrm{H}_{2} \mathrm{~S}$-degrading culture obtained from the activated sludge of the wastewater treatment plant of a resin-producing industry was enriched in a biofilter. The biomass was acclimated to sulfur compounds in a sodium thiosulfate mineral medium. 
The composition of the liquid medium used16 was (in $\mathrm{g} \mathrm{L}^{-1}$ ): $\mathrm{KH}_{2} \mathrm{PO}_{4}, 2 ; \mathrm{K}_{2} \mathrm{HPO}_{4}, 2$; $\mathrm{NH}_{4} \mathrm{Cl}, 0.4 ; \mathrm{MgCl}_{2} .6 \mathrm{H}_{2} \mathrm{O}, 0.2 ; \mathrm{FeSO}_{4} .7 \mathrm{H}_{2} \mathrm{O}, 0.01$ and $\mathrm{Na}_{2} \mathrm{~S}_{2} \mathrm{O}_{3} .5 \mathrm{H}_{2} \mathrm{O}, 8$.

The total suspended solids (TSS) and volatile suspended solids (VSS) were occasionally analysed to monitor the biomass growth. After a few days, it was found that some elemental sulfur was formed in the water phase and that the $\mathrm{pH}$ dropped slightly. Then the sludge was recirculated through the reactor in order to get enough biofilm growth on the Pall rings. After that, the $\mathrm{pH}$ of the liquid dropped much faster than before. Sulfate was produced from the complete oxidation of sulfide instead of a partial oxidation of sulfide. The $\mathrm{pH}$, sulfate, and $\mathrm{H}_{2} \mathrm{~S}$ concentrations were monitored daily. Besides measuring VSS concentrations, the bacterial growth was also observed under the microscope.

\section{Experimental set-up}

The schematic of the biotrickling filter used in this study is shown in Fig 1 . It is a cylindrical packed bed reactor made of glass, $75 \mathrm{~mm}$ in diameter and $700 \mathrm{~mm}$ in height. The active height of the packed column, filled with polypropylene Pall rings (VFF GmbH \& Co, Ransbach-Baumbach, Germany), was $640 \mathrm{~mm}$. The Pall ring bed had an initial porosity of $91 \%$ and a specific surface area of $350 \mathrm{~m}^{2} \mathrm{~m}^{-3}$. The cylindrical glass column contained four equidistant sampling ports. All fittings, connections and tubings were made of Teflon. $\mathrm{H}_{2} \mathrm{~S}$ was introduced by passing the air stream over an $\mathrm{H}_{2} \mathrm{SO}_{4}$ solution into which a solution of $\mathrm{Na}_{2} \mathrm{~S}$ was dripped. Gas phase $\mathrm{H}_{2} \mathrm{~S}$ concentrations ranging from 0 to $190 \mathrm{ppm}$ were obtained by changing the $\mathrm{Na}_{2} \mathrm{~S}$ concentration and/or dripping rate. The resulting synthetic waste gas was introduced through the bottom of the column (counter-current flow). The aqueous mineral medium described above, without $\mathrm{Na}_{2} \mathrm{~S}_{2} \mathrm{O}_{3}$, was continuously recirculated over the packed bed using two peristaltic pumps, models TR11 4RU and 323E/D (Watson-Marlow Ltd, Falmouth, Cornwall, UK ) at volumetric flow rates of $0.75-12.13 \mathrm{~L} \mathrm{~h}^{-1}$.

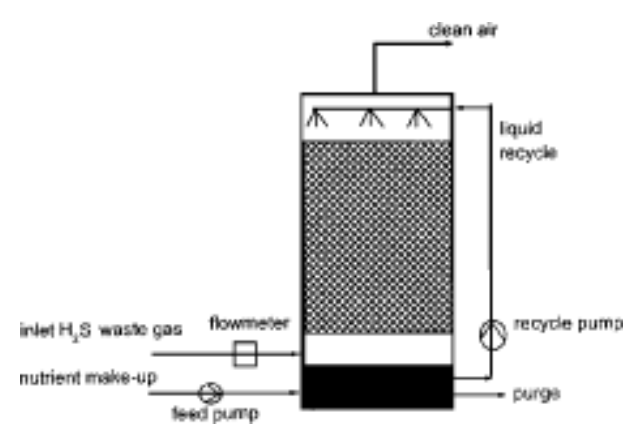

Figure 1.

Schematic of the laboratory-scale biotrickling filter.

\section{Analytical methods}

The hydrogen sulfide concentration was determined using a sensor (Dräger Sensor XSEC $\mathrm{H}_{2} \mathrm{~S}$ HC6809180). The $\mathrm{pH}$ was measured with a Crison $\mathrm{pH}$-meter 507, using a combined glass electrode. Sulfate analysis was carried out photometrically by the turbidimetric method, which was performed by measuring the absorbance on a 
spectrophotometer (Hitachi, Model U-2001UV/Vis; Pacisa \& Giralt, Madrid, Spain). All TSS and VSS measurements were performed according to standard methods.17

\section{RESULTS AND DISCUSSION}

\section{$\mathrm{H}_{2} \mathrm{~S}$ removal efficiency in continuous operation}

Increasing $\mathrm{H}_{2} \mathrm{~S}$ concentrations were fed to the biotrickling filter at a constant gas flow rate. To establish operating criteria necessary to scale-up the biotrickling filter, the relationship between the inlet loading of $\mathrm{H}_{2} \mathrm{~S}$ and the elimination capacity was estimated. The results are reported in Fig 2. The elimination capacity is defined as the amount of pollutant degraded per unit of time, normalized to the volume of packed bed. This plot allows for the comparison of bioreactors of different sizes operated under different conditions. As shown in Fig 2, the relationship between the load and the removal rate first rises and then levels off at its maximum value. The critical loading (ie complete removal capacity) was determined as $22.5 \mathrm{~g} \mathrm{H}_{2} \mathrm{~S} \mathrm{~m}^{-3}$ reactor $\mathrm{h}^{-1}$. Compared with data reported in the literature for autotrophic biological systems in which peat or lava rock were used as support, our biotrickling filter performed better.18, 19

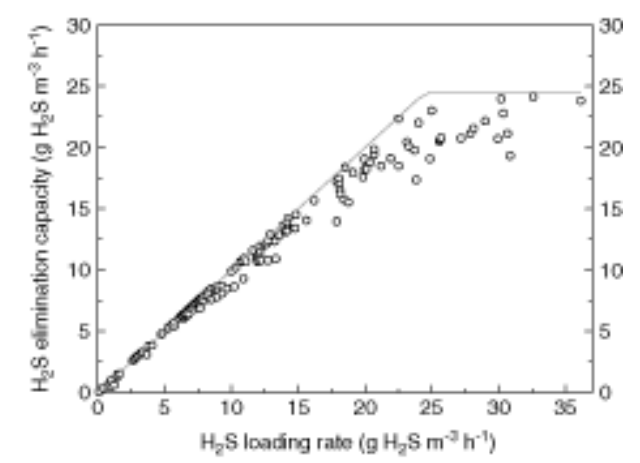

Figure 2.

Relationship between $\mathrm{H}_{2} \mathrm{~S}$ loading and elimination capacity.

\section{Effect of the retention time on $\mathrm{H}_{2} \mathrm{~S}$ removal}

Pollutant removal in the biotrickling filter takes place in two steps. First, $\mathrm{H}_{2} \mathrm{~S}$ is removed from the gas phase by diffusing into the liquid phase or biofilm; then $\mathrm{H}_{2} \mathrm{~S}$ is metabolized by the autotrophic microorganisms. The effect of the retention time on $\mathrm{H}_{2} \mathrm{~S}$ removal was studied by feeding $55 \mathrm{ppm}_{2} \mathrm{~S}$ to the bioreactor while applying variable gas flow rates. The results are shown in Fig 3. The bioreactor reached high removal efficiencies of more than 99\% when the empty bed retention time (EBRT) was in the range of $28-84 \mathrm{~s}$. The $\mathrm{H}_{2} \mathrm{~S}$ removal efficiency dropped to $73 \%$ when the gas retention time was decreased to $14 \mathrm{~s}$. Related studies indicated that the microorganisms can metabolize hydrogen sulfide within 1-2 s.20 Hence, the reduction of removal efficiency at this short retention time was most probably caused by the slow diffusion of $\mathrm{H}_{2} \mathrm{~S}$ from the gas phase into the liquid phase. In many waste gases as, for example, in polluted air generated at wastewater treatment plants, $\mathrm{H}_{2} \mathrm{~S}$ concentrations are quite low. When lowering the $\mathrm{H}_{2} \mathrm{~S}$ concentration to $12 \mathrm{ppm}$, complete pollutant removal was reached even at a short EBRT of $11 \mathrm{~s}$. 


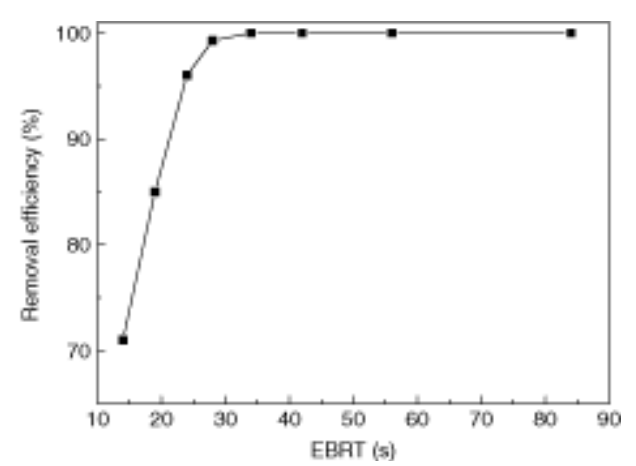

Figure 3.

Effect of the empty bed retention time of the gas on the $\mathrm{H}_{2} \mathrm{~S}$ removal efficiency at a feed concentration of 55 ppm.

\section{Effect of the superficial gas velocity}

From a process engineering point of view the gas flow rate is expected to have a considerable effect on the reactor's performance as it is directly linked to its mean residence time. In order to verify this influence, experiments were carried out in which the biotrickling filter's performance was determined at different gas flow rates. Each flow rate was maintained for at least 2 weeks.

As mentioned above, $\mathrm{H}_{2} \mathrm{~S}$ removal can be described as a stepwise process going first through a sequence of mass transfer steps from the gas phase to the liquid phase and biofilm, to be ultimately biodegraded in the biofilm.

The rate of mass transfer is dependent on the concentration gradient across the gasliquid interface and can be defined as:

Mass flux $=K_{1}\left(\frac{C_{\mathrm{g}}}{H}-C_{1}\right)$

where $K_{\mathrm{l}}=$ mass transfer coefficient, $C_{\mathrm{g}}=\mathrm{H}_{2} \mathrm{~S}$ gas concentration, $C_{\mathrm{l}}=\mathrm{H}_{2} \mathrm{~S}$ liquid concentration, $H=$ dimensionless Henry's constant.

When the gas phase concentration is low, mass transfer is usually the limiting step; otherwise biodegradation would be rate-limiting.

In Fig 4 the measured trickling filter's elimination capacity is plotted for different inlet $\mathrm{H}_{2} \mathrm{~S}$ concentrations at a constant liquid flow rate of $2.77 \mathrm{~L} \mathrm{~h}^{-1}\left(0.627 \mathrm{~m} \mathrm{~h}^{-1}\right)$ and at gas flow rates of 5,6 , and $7 \mathrm{~L} \mathrm{~min}^{-1}$, corresponding to superficial gas velocities of 68,81 , and $95 \mathrm{~m} \mathrm{~h}^{-1}$ and EBRT of 34, 28, and 24 s. From this figure, it can be observed that the elimination capacity increased when increasing the gas flow rate over all the concentration range studied. At $7 \mathrm{~L} \mathrm{~min}^{-1}$ a maximum elimination capacity of $24 \mathrm{~g} \mathrm{H}_{2} \mathrm{~S}$ $\mathrm{m}^{-3} \mathrm{~h}^{-1}$ was obtained, while at 5 and $6 \mathrm{~L} \mathrm{~min}^{-1}$ the capacities obtained were 21 and $22 \mathrm{~g}$ $\mathrm{H}_{2} \mathrm{~S} \mathrm{~m}^{-3} \mathrm{~h}^{-1}$, respectively. As small fluctuations of the elimination capacity are known to exist in a continuously operating trickling filter, the maximum elimination capacity values found at each gas flow rate can be regarded as being very similar. 


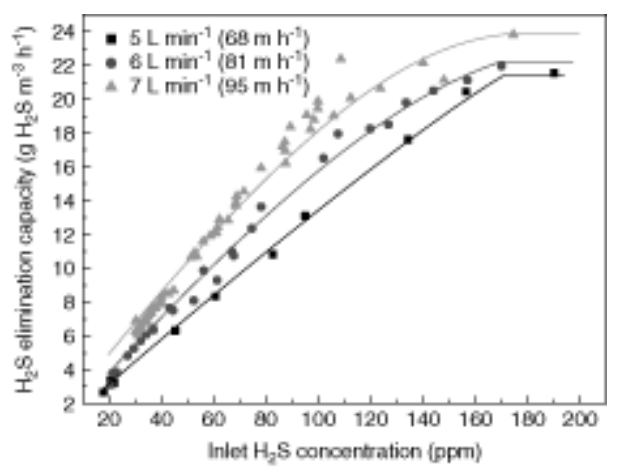

\section{Figure 4.}

Elimination capacity as a function of the inlet concentration of $\mathrm{H}_{2} \mathrm{~S}$, at different flow rates of the gas stream.

\section{Effect of the flow rate of the liquid phase}

In biotrickling filters, due to the recirculation of a liquid phase, the sulfuric acid produced can be removed from the filter bed, and it is also possible to control physiological conditions in the liquid phase (nutrient supply, contaminant absorption, removal of metabolites, and biofilm moistening). Apart from affecting the optimal conditions for the biological reaction, the liquid flow may also influence the system's performance by acting on the formation and the thickness of the biofilm; thus affecting the maximum elimination capacity that can be reached. In this study, the effect of the flow rate of the recirculated liquid on the elimination capacity of $\mathrm{H}_{2} \mathrm{~S}$ was investigated. During the test period, the EBRT was set at $24 \mathrm{~s}$, and the influent $\mathrm{H}_{2} \mathrm{~S}$ concentration ranged from 25 to $150 \mathrm{ppm}$. Four different liquid flow rates of 2.77, 4.08, 6.10, and $12.13 \mathrm{~L} \mathrm{~h}^{-1}$ were used, corresponding to linear velocities of $0.627,0.924,1.381$ and $2.747 \mathrm{~m} \mathrm{~h}^{-1}$. The results are presented in Fig 5. The $\mathrm{H}_{2} \mathrm{~S}$ elimination capacity is shown for the different liquid flow rates.

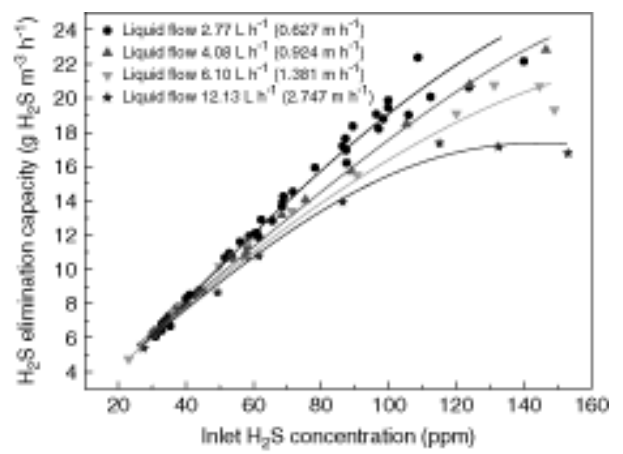

Figure 5.

Elimination capacity as a function of the inlet $\mathrm{H}_{2} \mathrm{~S}$ concentration, at different liquid flow rates.

As might have been expected, Fig 5 indicates that the elimination capacity increases with the inlet concentration. Although the range of liquid flow rates was relatively narrow $\left(0.627-2.747 \mathrm{~m} \mathrm{~h}^{-1}\right)$, it appears that the higher the liquid flow rate, the lower the 
slope, meaning that, for a constant gas residence time, the amount of pollutant being degraded is lower when decreasing the liquid residence time, ie increasing its flow rate. This may be due to the increase of the thickness of the liquid phase at higher liquid flow rates, causing mass transfer limitation between the gas phase and the liquid/biofilm phase.

The flow rate of the trickling phase may affect the mass transfer rate of the pollutant from the air to the biocatalyst as well as the removal of potentially inhibitory metabolites. The effect of the flow rate of the recirculated liquid on the reactor's performance has also been studied by other authors but mainly for Volatile Organic Compounds instead of Volatile Inorganic Compounds as $\mathrm{H}_{2} \mathrm{~S}$. Diks and Ottengraf21, 22 reported that the water flow rate strongly influences the removal of dichloromethane (DCM) in a trickling biofilter. Hartmans and Tramper23 observed a linear relationship between the liquid recirculation rate and DCM removal in a trickling biofilter. Other more recent studies have also examined or mentioned the effects of the flow rate of the liquid recirculated on the removal efficiency of VOC. Casey et al24 reported that the liquid flow velocity has a strong influence on the biofilm development in a membraneaerated biofilm reactor, using Vibrio natriegens as a test organism and acetate as carbon substrate. The velocity had also an effect on mass transfer in the diffusion boundary layer, on the biomass detachment rate from the biofilm, and on the maximum biofilm thickness reached. Chou and Huang25 used a biotrickling filter with plastic packings for the treatment of methylethylketone (MEK). Liquid flow rates of $0.5,1.0$, and $2.0 \mathrm{~m}^{3} \mathrm{~m}^{-2}$ $\mathrm{h}^{-1}$ were tested for constant MEK loadings of 14.3, 36.6, and $75.3 \mathrm{~g} \mathrm{~m}^{-3} \mathrm{~h}^{-1}$. Their results showed that for treating water-soluble contaminants such as MEK, the liquid recirculation rate is a minor operational factor in the case of low loadings between 14.3 and $36.6 \mathrm{~g} \mathrm{~m}^{-3} \mathrm{~h}^{-1}$, such that there are only minute residual contaminant concentrations in the liquid. However, high velocities of liquid recirculation should be avoided at high levels of contaminant loadings such as $75.3 \mathrm{~g} \mathrm{~m}^{-3} \mathrm{~h}^{-1}$. Under such conditions, some contaminant remaining in the liquid would be stripped from the liquid. Chou and Huang26 used a biotrickling filter with blast-furnace slag packings for the treatment of ethylether in an air stream. Liquid velocities of 3.63, 5.73, 7.64, and $9.55 \mathrm{~m}^{3} \mathrm{~m}^{-2} \mathrm{~h}^{-1}$ were tested for a constant ethylether loading of $38 \mathrm{~g} \mathrm{~m}^{-3} \mathrm{~h}^{-1}$. Their results showed that the ethylether removal efficiency was nearly independent of the liquid recirculation rate.

The results of the present work and other published studies reveal that there are still no consistent results as to the effects of the liquid recirculation rate on the pollutant's removal efficiency in biotrickling filters. However, for conditions of relatively low loadings, under which almost all influent contaminants can be eliminated, a liquid flow rate in the range of $0.05-10 \mathrm{~m}^{3} \mathrm{~m}^{-2} \mathrm{~h}^{-1}$ can be used and has been applied in many practical applications. Such rates should be enough for nutrient addition, metabolite removal, and biofilm moistening. On the other hand, different conditions should be tested to find a proper rate at high contaminant loadings for each specific system.

\section{Effect of pH on $\mathrm{H}_{2} \mathrm{~S}$ removal}

The biodegradation of $\mathrm{H}_{2} \mathrm{~S}$ produces sulfuric acid. Since there is no biotransformation consuming the acid, the latter will accumulate very fast, and the $\mathrm{pH}$ will drop to the point where the microbial ecosystem is inhibited. 
In the present experiments, after renewing the nutrient solution with its $\mathrm{pH}$ adjusted to 6.78, the $\mathrm{pH}$ fluctuations of the trickling liquid were monitored over time. One hour after renewing the solution, the $\mathrm{pH}$ of the trickling liquid reached a value of around 3.0, and continued decreasing more slowly to about 2.0 over a period of several hours (Fig $6)$. However, there was no inhibitory effect on the removal of $\mathrm{H}_{2} \mathrm{~S}$.

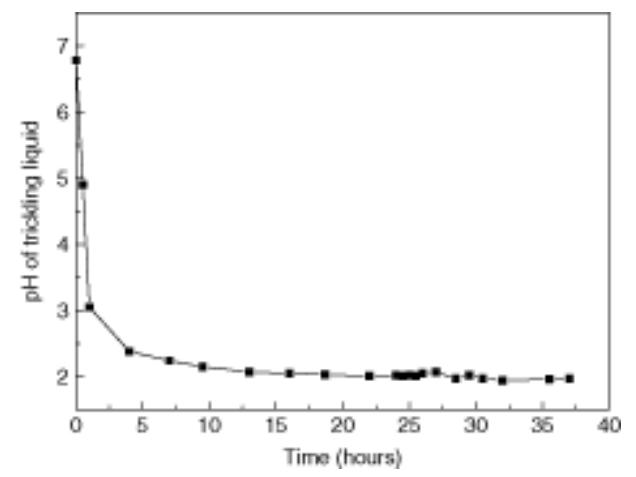

\section{Figure 6.}

Evolution of the $\mathrm{pH}$ of the trickling liquid vs time.

The effect of the $\mathrm{pH}$ on the removal of $\mathrm{H}_{2} \mathrm{~S}$ was examined over a $\mathrm{pH}$ range of 2-7. The $\mathrm{pH}$ of the trickling liquid was measured every hour and was controlled and adjusted by adding an $\mathrm{NaHCO}_{3}$ solution when the $\mathrm{pH}$ deviated from the expected value. Each specific $\mathrm{pH}$ value was kept for two consecutive days. Figure 7 represents the removal efficiencies and elimination capacities vs $\mathrm{pH}$.

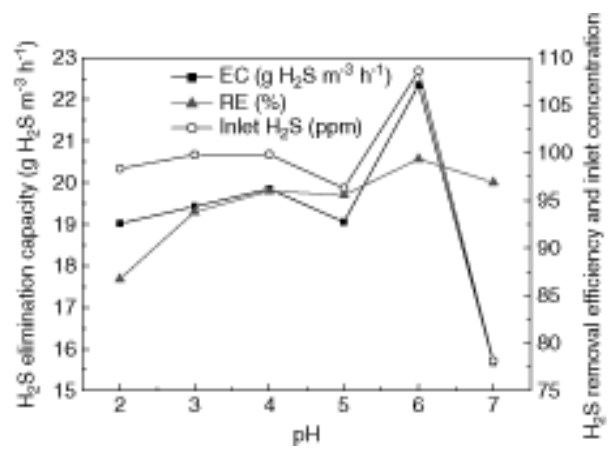

\section{Figure 7.}

Elimination capacity of the biotrickling filter as a function of $\mathrm{pH}$.

Figure 7 shows that the removal efficiency remained high, above 95\%, between $\mathrm{pH} 4$ and 7 , and then dropped slightly to 94 and $87 \%$ at $\mathrm{pH} 3$ and 2, respectively. From a practical point of view, the biotrickling filter can be operated at low $\mathrm{pH}$, ie $2-4$, because simple water washing is sufficient to remove hydrogen ions as fast as they form. 


\section{Effect of sulfate concentration on $\mathrm{H}_{2} \mathrm{~S}$ removal}

The biological oxidation of sulfide to sulfate proceeds in two stages. In the first stage, sulfide loses two electrons and membrane-bound polymeric sulfur compounds are being formed. In the second step, this sulfur is oxidized to sulfite and then to sulfate.

$2 \mathrm{HS}^{-}+\mathrm{O}_{2} \longrightarrow 2 \mathrm{~S}^{0}+2 \mathrm{OH}^{-}(1)$

$2 \mathrm{~S}^{0}+3 \mathrm{O}_{2} \longrightarrow 2 \mathrm{SO}_{4}{ }^{2-}+2 \mathrm{H}^{+}(2)$

High concentrations of sulfate are toxic to the microorganisms. Yang and Allen5, 6 reported that the critical level is between 30 and $40 \mathrm{mg} \mathrm{S}$ (g dry compost) $^{-1}$ in a biofilter packed with compost. In the present study, after one day of operation, at an influent $\mathrm{H}_{2} \mathrm{~S}$ concentration of $75 \mathrm{ppm}$, a gas flow rate of $7 \mathrm{~L} \mathrm{~min}^{-1}$, and a liquid flow rate of $2.77 \mathrm{~L}$ $\mathrm{h}^{-1}$, the $\mathrm{pH}$ of the recirculated liquid decreased from 6.8 to a stable value of 2.0. As shown in Figs 8 and 9, when the sulfate concentration in the liquid reached around 1900 $\mathrm{mg} \mathrm{L}^{-1}$, the removal efficiency significantly dropped from more than $90 \%$ to less than $80 \%$ while the $\mathrm{pH}$ remained basically constant. This suggests that the biological activity in the filter bed is strongly inhibited by a high sulfate content and a low $\mathrm{pH}$. From the results, it was found that the sulfate accumulation is an important factor in the operation of a biotrickling filter treating $\mathrm{H}_{2} \mathrm{~S}$-polluted air, observing significant inhibition at concentrations close to $1900 \mathrm{mg} \mathrm{L}^{-1}$. Thus, it is necessary to avoid inhibition by sulfate and remove it from the recirculated liquid.

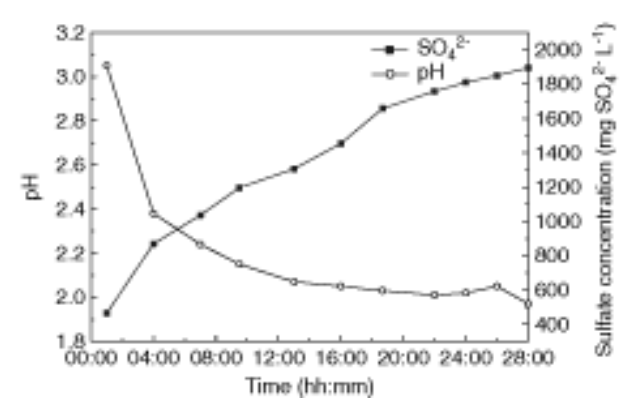

\section{Figure 8.}

Change of pH and sulfate concentration with time.

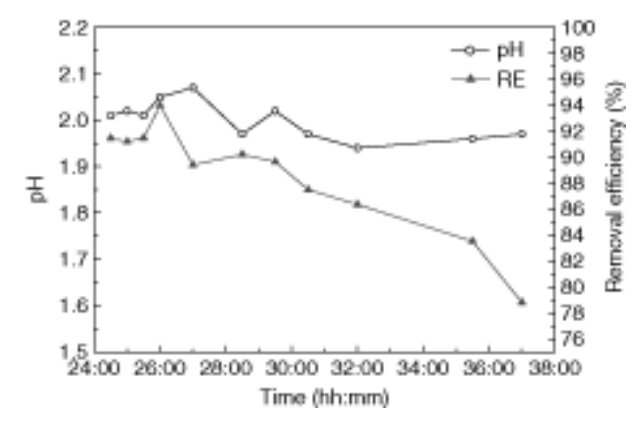

\section{Figure 9.}

Removal efficiency (RE) of $\mathrm{H}_{2} \mathrm{~S}$ when the sulfate concentration reached $1900 \mathrm{mg} \mathrm{L}^{-1}$ (see Fig 8). 


\section{CONCLUSIONS}

The results from the present investigation concerning the autotrophic removal of $\mathrm{H}_{2} \mathrm{~S}$ from waste gases in a biotrickling filter packed with Pall rings show that a stable performance can be achieved in long-term operation. This bioreactor system has a number of inherent advantages, including the possibility of reaching relatively high removal efficiencies and a low pressure drop with no need of an additional carbon source as a result of working with autotrophs grown on an inert carrier. Removal efficiencies between $80 \%$ and $100 \%$ were reached at inlet $\mathrm{H}_{2} \mathrm{~S}$ concentrations of up to $190 \mathrm{ppm}$ for surface loadings ranging from 68 to $95 \mathrm{~m}^{3} \mathrm{~m}^{-2} \mathrm{~h}^{-1}$ and liquid flow rates between 2.77 and $12.13 \mathrm{~L} \mathrm{~h}^{-1}$. The maximum elimination capacity of the biotrickling filter was found to be $24 \mathrm{~g} \mathrm{H}_{2} \mathrm{~S} \mathrm{~m}^{-3}$ reactor $\mathrm{h}^{-1}$. When maintaining a suitable gas flow rate, recirculating liquid flow rate and salt removal rate, the reactor's performance could be maintained at high, stable levels for long periods of time. The performance started declining at $\mathrm{pH}$ values below 3-4 and sulfate concentrations exceeding $1900 \mathrm{mg} \mathrm{L}^{-1}$. Thus, biofiltration proved to be an effective alternative to conventional treatment techniques for the removal of hydrogen sulfide from waste gases.

\section{Acknowledgements}

The present research was financed by the Spanish Ministry of Science and Technology (Project PPQ2001-0557). Yaomin Jin was financially supported through a fellowship of the Agencia Española de Cooperación Internacional (AECI) and the Spanish Ministry of Foreign Affairs.

\section{REFERENCES}

- Wani AH, Branion RMR and Lau AK, Biofiltration: a promising and cost-effective control technology for odors, VOCs and air toxics. J Environ Sci Health Part AToxic/Hazard Subst Environ Eng 32: 2027-2055 (1997).

- 2Kennes $C$ and Veiga MC, Conventional biofilters in Bioreactors for Waste Gas Treatment, ed by KennesC and VeigaMC. Kluwer Academic Publishers, Dordrecht, The Netherlands, pp 47-98 (2001).

- 3Kennes $C$ and Thalasso F, Waste gas biotreatment technology. J Chem Technol Biotechnol 72: 303-319 (1998).

- 4Jin YM and Chen JM, Applications of biofiltration in air pollution control processes. Techniques and Equipment for Environmental Pollution Control 2: 76-80 (2001).

- 5Yang YH and Allen ER, Biofiltration control of hydrogen sulfide: 1. Design and operational parameters. J Air Waste Manage Assoc 44: 863-868 (1994).

- 6Yang YH and Allen ER, Biofiltration control of hydrogen sulfide: 2. Kinetics, biofilter performance, and maintenance. J Air Waste Manage Assoc 44: 1315-1321 (1994).

- 7Chung YC, Huang CP and Tseng CP, Biodegradation of hydrogen sulfide by a laboratory-scale immobilized Pseudomonas putida CH11 biofilter. Biotechnol Prog 12: 773-778 (1996).

- 8Chung YC, Huang CP, Pan JR and Tseng CP, Comparison of autotrophic and mixotrophic biofilters for $\mathrm{H}_{2} \mathrm{~S}$ removal. J Environ Eng-ASCE 124: 362-367 (1998). 
- 9Chitwood DE, Devinny JS and Reynolds FE, Evaluation of a two-stage biofilter for treatment of POTW waste air. Environ Prog 18: 212-221 (1999).

- 10Kennes $C$ and Veiga MC, Inert filter media for the biofiltration of waste gasescharacteristics and biomass control. Re/Views Environ Sci Bio/Technol 1: 201-214 (2002).

- 11 Webster TS, Devinny JS, Torres EM and Basrai SS, Biofiltration of odors, toxics and volatile organic compounds from publicly owned treatment works. Environ Prog 15: 141-147 (1996).

- 12Wani AH, Branion RMR and Lau AK, Effects of periods of starvation and fluctuating hydrogen sulfide concentration on biofilter dynamics and performance. $J$ Hazard Mater 60: 287-303 (1998).

- 13Nakada Y and Ohta Y, Purification and properties of hydrogen sulfide oxidase from Bacillus sp BN53-1. J Biosci Bioeng 87: 452-455 (1999).

- 14Morgan-Sagastume JM, Noyola A, Revah S and Ergas SJ, Changes in physical properties of a compost biofilter treating hydrogen sulfide. J Air Waste Manage Assoc 53: 1011-1021 (2003).

- 15Van Lith C, Leson $G$ and Michelsen R, Evaluating design options for biofilters. $J$ Air Waste Manage Assoc 47: 37-48 (1997).

- 16Chung YC, Huang $C$ and Tseng CP, Removal of hydrogen sulfide by immobilized Thiobacillus sp CH11 in a bioreactor. J Chem Technol Biotechnol 69: 58-62 (1997).

- 17APHA, Standard Methods for the Examination of Water and Wastewater, 20th edn. American Public Health Association, Washington, DC, pp 4-178 (1998).

- 18Furusawa N, Togashi I, Hirai M, Shoda M and Kubota H, Removal of hydrogen sulfide by a biofilter with fibrous peat. J Ferment Technol 62: 589-594 (1984).

- 19Chitwood DE and Devinny JS, Treatment of mixed hydrogen sulfide and organic vapors in a rock medium biofilter. Water Environ Res 73: 426-435 (2001).

- 20Sublette KL and Sylvester ND, Oxidation of hydrogen sulfide by Thiobacillus denitrificans desulfurization of natural gas. Biotechnol Bioeng 29: 249-257 (1987).

- 21Diks RMM and Ottengraf SPP, Verification studies of a simplified model for the removal of dichloromethane from waste gases using a biological trickling filter (Part I). Bioprocess Eng 6: 93-99 (1991).

- 22Diks RMM and Ottengraf SPP, Verification studies of a simplified model for the removal of dichloromethane from waste gases using a biological trickling filter (Part II). Bioprocess Eng 6: 131-140 (1991).

- 23Hartmans $S$ and Tramper J, Dichloromethane removal from waste gases with a trickle bed bioreactor. Bioprocess Eng 6: 83-92 (1991).

- 24Casey E, Glennon B and Hamer G, Biofilm development in a membrane-aerated biofilm reactor: effect of flow velocity on performance. Biotechnol Bioeng 67: 476-486 (2000).

- $25 C h o u ~ M S$ and Huang JJ, Treatment of methylethylketone in air stream by biotrickling filters. J Environ Eng-ASCE 123: 569-576 (1997).

- 26Chou MS and Huang YS, Treatment of ethylether in air stream by a biotrickling filter packed with slags. J Air Waste Manage Assoc 49: 533-543 (1999). 